\title{
Open versus laparoscopic partial nephrectomy for clinical T1a renal masses: a matched-pair comparison of 280 patients with TRIFECTA outcomes (RECORd Project)
}

\author{
Andrea Minervini - Giampaolo Siena • Alessandro Antonelli - Giampaolo Bianchi • \\ Aldo Massimo Bocciardi - Sergio Cosciani Cunico • Vincenzo Ficarra • Cristian Fiori • \\ Ferdinando Fusco - Andrea Mari - Giuseppe Martorana - Mauro Medica • Vincenzo Mirone • \\ Giuseppe Morgia - Francesco Porpiglia - Francesco Rocco - Bruno Rovereto Riccardo Schiavina \\ Claudio Simeone $\cdot$ Carlo Terrone Alessandro Volpe $\cdot$ Marco Carini $\cdot$ Sergio Serni • \\ and Members of the RECORd Project-LUNA Foundation
}

Received: 26 June 2013/ Accepted: 14 August 2013

(C) Springer-Verlag Berlin Heidelberg 2013

\begin{abstract}
Aim of the study To report a matched-pair comparative analysis between open (OPN) and laparoscopic partial nephrectomy (LPN) for clinical (c) T1a renal masses from a large prospective multicenter dataset.

Materials and methods The RECORd Project includes all patients who underwent OPN and LPN for kidney cancer between January 2009 and January 2011 at 19 Italian centers. Open and laparoscopic groups were compared regarding clinical, surgical, pathologic, functional results
\end{abstract}

A. Minervini · G. Siena ( $)$ - A. Mari · M. Carini · S. Serni Clinica Urologica I, AOUC, Università di Firenze, Florence, Italy

e-mail: giampaolo.siena@gmail.com

A. Antonelli · S. Cosciani Cunico - C. Simeone Unità Operativa di Urologia Dipartimento di NefroUrologia,

Azienda AO Spedali Civili di Brescia, Brescia, Italy

G. Bianchi

Policlinico di Modena, Clinica Urologica,

Università di Modena, Modena, Italy

A. M. Bocciardi

Dipartimento Chirurgico Polispecialistico, Urologia, Azienda

Ospedaliera Ospedale Niguarda Ca' Granda, Milan, Italy

V. Ficarra

Clinica Urologica, Università di Padova, Padua, Italy

C. Fiori · F. Porpiglia

Divisione di Urologia, Università di Torino, Ospedale San Luigi

Gonzaga, Orbassano, Torino, Italy

F. Fusco $\cdot$ V. Mirone

Policlinico Federico II, Università di Napoli, Naples, Italy and TRIFECTA outcome. Multivariable logistic regression models were used to analyze predictors of WIT $>25 \mathrm{~min}$, surgical complications (SC) and the achievement of the TRIFECTA outcome.

Results Overall, 301 patients had OPN and 149 LPN. Groups were matched 1:1 (140 matched pairs) for clinical diameter, tumor location and type of indication. Laparoscopic partial nephrectomy was associated with a significantly mean longer WIT (19.9 vs. $15.1 \mathrm{~min} ; p<0.001)$, and it was an independent predictor of a WIT $>25$ min (RR 6.29, $p<0.0001$ ). The TRIFECTA was achieved in

G. Martorana $\cdot$ R. Schiavina

Dipartimento di Urologia, Università di Bologna, Ospedale S.

Orsola-Malpighi, Bologna, Italy

M. Medica

Ospedale Sestri Levante, Sestri Levante, Italy

G. Morgia

Luna Foundation, Rome, Italy

F. Rocco

UOC Urologia Ospedale Maggiore Ca' Granda Policlinico

Mangiagalli Regina Elena Università degli Studi di Milano,

Milan, Italy

B. Rovereto

I.R.C.C.S. Policlinico San Matteo, Struttura Di Urologia,

Pavia, Italy

C. Terrone $\cdot$ A. Volpe

Dipartimento di Urologia, Azienda Ospedaliera Maggiore

Della Carità, Università del Piemonte Orientale,

Novara, Italy 
78.6 and $74.3 \%$ after OPN and LPN ( $p=n s)$, respectively, and the surgical approach was not a predictor of a negative TRIFECTA and SC at multivariable analysis. At 6-month follow-up, no significant differences were observed between the OPN and LPN group both in estimated glomerular filtration rate (eGFR) $(\Delta \mathrm{GFR} 1.1 \mathrm{vs}$. $4.1 \mathrm{~mL} / \mathrm{min}$ ) and in new-onset stage III-V chronic kidney disease $(\mathrm{CKD})$ rate $(0$ vs. $0.7 \%)$.

Conclusion No significant difference in achieving the TRIFECTA outcome was reported after OPN and LPN. LPN was associated with a significantly longer WIT. However, eGFR at 6-month follow-up did not differ significantly between the two surgical approaches.

Keywords Laparoscopic partial nephrectomy · Open partial nephrectomy · Kidney cancer . Laparoscopic versus open matched-pair comparison . TRIFECTA

\section{Introduction}

Incidental diagnosis of small renal masses (SRMs) is increased because of improvement and widespread use of imaging techniques [1]. Despite recent developments in probe-ablative therapies, surgical excision remains the cornerstone of treatment [2]. Open partial nephrectomy (OPN) performed with the excision of a minimal tumorfree surgical margin or as simple enucleation (SE) is considered the gold standard for the treatment of SRMs [3, 4]. Laparoscopic PN (LPN) is a viable treatment option; nevertheless, it continues to be performed in a minority of centers [5-7]. Indeed, LPN has been associated in some retrospective observational studies with a steep learning curve, more postoperative complications, particularly urological, and an increased number of subsequent procedures [7]. To compare the two approaches, we report a matchedpair analysis between OPN and LPN for cT1a SRMs from a large prospective multicenter dataset, evaluating clinical, surgical, pathologic, functional results and the simultaneous achievement of the TRIFECTA outcomes (defined as warm ischemia time $<25 \mathrm{~min}$, negative surgical margins and no perioperative complications) [8,9].

\section{Patients and methods}

The Italian Registry of Conservative Renal Surgery (RECORd Project) is a 4-year prospective observational multicenter study promoted by the Leading Urological No profit foundation Advanced (LUNA) research of the Società Italiana di Urologia (SIU). The study includes all patients who underwent OPN and LPN for radiologically diagnosed SRMs between January 2009 and January 2011 at 19 urological Italian centers. An online database was generated, and it comprises five main folders: (1) Anthropometric and Preoperative data; (2) Imaging, Indications and Comorbidities; (3) Intraoperative Data; (4) Postoperative Data; and (5) Histopathological Analysis. All data were centrally recorded on a data server.

Overall, information about 554 patients was collected. Surgical indications were defined as elective (localized unilateral RCC with healthy contralateral kidney), relative (localized unilateral RCC with the coexistence of comorbidities such as diabetes, hypertension and lithiasis that could potentially affect kidney function in the future) and absolute (bilateral tumors, multiple tumors, moderate to severe chronic kidney disease or in case of neoplasia involving an anatomically or functionally solitary kidney).

The laparoscopic and open approaches as well as the surgical technique, performed in the form of PN and SE, were adopted according to the center's and surgeon's preference. Standard PN has been defined as the excision of the tumor and of a minimal margin of healthy peritumoral renal parenchyma [3]. SE has been defined as the blunt tumor excision without removing a visible rim of parenchymal tissue around the pseudocapsule [3].

All significant patients' and tumors' characteristics were collected. Performance status was assigned according to the ECOG criteria [10]. Mode of presentation was distinguished according to the Patard classification [11].

Tumors were classified according to their location on the longitudinal plane (upper pole, middle part and lower pole) and on the transverse plane (anterior surface, posterior surface, lateral margin, medial margin, perihilar) of the kidney. Perihilar position was defined as tumor in contiguity with main artery or vein and/or first-order branches at the preoperative imaging. According to the degree of depth into the kidney, each tumor was also classified into three growth pattern categories: (1) prevalently $(\geq 50 \%)$ exophytic, (2) prevalently endophytic ( $<50 \%$ exophytic) and (3) completely endophytic.

All surgical specimens were processed according to the standard pathologic procedures at each institution by experienced uropathologists. Tumors were pathologically staged according to the American Joint Committee on Cancer-Union Internationale Contre le Cancer TNM classification, and surgical margin status was reported [12]. The Heidelberg and Fuhrman classifications were used to assign the histologic type and nuclear grade, respectively $[13,14]$.

The severity of surgical complications was graded according to the modified Clavien system [15].

TRIFECTA outcome was defined as a combination of warm ischemia time (WIT) $<25 \mathrm{~min}$, negative surgical margins and no perioperative complications $[8,9]$. 
Renal function was measured as creatinine level and estimated glomerular filtration rate (eGFR) using the Modification of Diet in Renal Disease (MDRD) formula, at baseline, third postoperative day and at 6-month follow-up. Chronic kidney disease (CKD) stage III-V rate was recorded at baseline and at 6-month follow-up.

\section{Statistical analysis}

A propensity score matching was performed to adjust for preoperative variables using $\mathrm{R}$ Project using multivariable logistic regression based upon the covariates: clinical tumor size (continue variable), type of indication and tumor location $[16,17]$. The matching was carried out with a 1:1 ratio with respect to the surgical approach (LPN vs. OPN) with a $\mathrm{C}$ statistic of 0.65 .

Continuous variables were reported as mean (SD) or as median and IQR, as appropriate. The Student's t test and the Mann-Whitney $U$ test were used to compare continuous variables, and the Pearson chi-square test was used to compare categorical variables. Multivariable logistic regression models were applied to analyze the predictors of WIT $>25 \mathrm{~min}$, surgical complications and TRIFECTA outcome. Statistical significance was set as $p \leq 0.05$. All reported $p$ values are two-sided. Analyses were performed with SPSS version 17.0 (SPSS Inc, Chicago, IL, USA) by two of the authors (AM, AM).

\section{Results}

A total of 554 patients were included in the dataset. Overall, 104 patients were excluded for the following reasons: T1b tumor stage (91 patients), metastatic disease (2 patients) and incomplete data (11 patients). Overall, 450 patients were the subject of the final analysis. Three hundred one had OPN and 149 LPN. Groups were matched 1:1 (140 matched pairs) for clinical diameter, tumor side and type of indication. Patients' and tumors' characteristics and intraoperative data for both treatment groups are reported in Table 1. No statistically significant differences between the two groups were present for age, performance status, symptoms at diagnosis, tumor growth pattern, preoperative hemoglobin, creatinine, eGFR as well as for the operative times (131 vs. $143 \mathrm{~min}$ ), the surgical technique (SE vs. standard PN) and hilar control.

Mean intraoperative blood loss (IBL) was slightly higher for the OPN group, but it did not reach the statistical significance ( 221 vs. $164 \mathrm{cc} ; p=\mathrm{ns}$ ). LPN was associated with significantly mean longer WIT compared to OPN (19.9 vs. $15.1 \mathrm{~min} ; p<0.001)$.

Factors predicting WIT $>25 \mathrm{~min}$ at the univariable analysis were the laparoscopic approach, tumor growth pattern $\geq 50 \%$ endophytic and mesorenal tumor location. At multivariable analysis, only the laparoscopic approach was confirmed as an independent predictors of a WIT $>25 \mathrm{~min}$. The risk of WIT $>25$ min in patients undergoing LPN was 6.3 times greater than in patients undergoing OPN (RR 6.29; $95 \%$ CI 2.47-16.07; $p<0.0001)$.

At the pathological analysis, the incidence of PSM was not significantly different between both groups (3.5 vs. $3 \%$, OPN vs. LPN), and at univariable analysis, the only factor that correlated with the risk of PSM was the type of indication (relative/absolute). Mean length of stay (SD) was 5 (3) and 6 (3) days in the LPN and OPN groups, respectively ( $p$ : 0.005).

Overall, 46 complications occurred, and no statistical difference was observed between the OPN and LPN groups (17.9 vs. $15 \%)$. Intraoperative SC rate was higher after OPN versus LPN ( 5 vs. $0.7 \%, p=0.03$ ). No statistically significant differences in Clavien grade II and III SC were seen between the two groups. No grade IV and V SC occurred in our series (Table 2). At the multivariable analysis, the factors independently associated with the risk of SC were clinical tumor size (RR 1.83; $95 \%$ CI 1.21-2.78; $p$ : 0.004) and the type of indication, with a threefold increased risk of $\mathrm{SC}$ in case of relative/absolute indication of PN.

No difference was observed in achieving the TRIFECTA outcome simultaneously after OPN versus LPN (78.6 vs. $74.3 \% ; p=\mathrm{ns}$ ). At multivariable analysis, tumor size and type of indication almost doubled the risk of not achieving the TRIFECTA (Table 3).

At 6-month follow-up, no difference in eGFR from baseline was observed between the OPN and LPN groups (1.1 vs. $4.1 \mathrm{~mL} / \mathrm{min} ; p=\mathrm{ns}$ ), and no significative difference in new-onset stage III-V CKD rate at 6-month follow-up with baseline was recorded ( 0 vs. $0.7 \% ; p=\mathrm{ns}$ ) (Table 2).

\section{Discussion}

In our study we report a high rate of simultaneous achievement of the TRIFECTA outcomes after OPN (78.6\%) and LPN (74.3\%), with no statistical difference between the two approaches. In a recent publication, Kalifeh et al. reported a $31.6 \%$ simultaneous achievement of the TRIFECTA outcome in a large single-surgeon LPN series; this lower rate can be explained by the preliminary worldwide experience with LPN at the time of their earlier cases and the different inclusion criteria used [8]. Indeed, data reported by Hung et al. in the "recent surgical era" where all T1 stages were included showed that the TRIFECTA outcomes were simultaneously achieved in $68 \%$ of the cases. The lower rate compared to the present paper can be explained by the slightly different definition of TRIFECTA made by the authors, defined as negative cancer margin, minimal renal 
Table 1 Preoperative patients' and tumor's characteristics

\begin{tabular}{|c|c|c|c|}
\hline & Open NSS & VLP NSS & $p$ \\
\hline \multicolumn{4}{|l|}{ Age } \\
\hline Mean, SD & $63.0(11.2)$ & $62.2(12.0)$ & 0.57 \\
\hline$\leq 65 n,(\%)$ & $68(48.6 \%)$ & $69(49.3 \%)$ & 0.95 \\
\hline$>65 n,(\%)$ & $72(51.4 \%)$ & $71(50.7 \%)$ & \\
\hline BMI, Mean (SD) & $26.6(4.2)$ & $26.1(3.6)$ & 0.29 \\
\hline Gender & & & 0.53 \\
\hline Male $n,(\%)$ & $87(62.1 \%)$ & $92(65.7 \%)$ & \\
\hline Female $n,(\%)$ & $53(37.9 \%)$ & $48(44.3 \%)$ & \\
\hline Tumor side & & & 0.83 \\
\hline Right $n,(\%)$ & $72(51.4 \%)$ & $71(50.7 \%)$ & \\
\hline Left $n,(\%)$ & $68(48.6 \%)$ & $69(49.3 \%)$ & \\
\hline$E C O G$ & & & 0.32 \\
\hline 0 & $87(62.1 \%)$ & $95(67.9 \%)$ & \\
\hline$\geq 1$ & $53(47.9 \%)$ & $45(32.1 \%)$ & \\
\hline Symptoms at diagnosis & & & 0.21 \\
\hline Asymptomatic & $119(85 \%)$ & $111(79.3 \%)$ & \\
\hline Symptomatic & $21(15 \%)$ & $29(20.7 \%)$ & \\
\hline $\begin{array}{l}\text { Clinical size, mean } \\
\text { (SD) }\end{array}$ & $2.48(0.8)$ & $2.46(0.8)$ & 0.85 \\
\hline Tumor location & & & 0.88 \\
\hline Polar & $81(57.9 \%)$ & $82(58.6 \%)$ & \\
\hline Mesorenal & $59(42.1 \%)$ & $58(41.4 \%)$ & \\
\hline Type of indication & & & 0.99 \\
\hline Elective & $117(83.6 \%)$ & $117(83.6 \%)$ & \\
\hline Absolute/Relative & $23(16.4 \%)$ & $23(16.4 \%)$ & \\
\hline Tumor growth pattern & & & 0.10 \\
\hline $\begin{array}{l}\text { Mainly exophytic } \\
(\geq 50 \%)\end{array}$ & $105(75 \%)$ & $113(80.7 \%)$ & \\
\hline $\begin{array}{l}\text { Mainly endophytic } \\
\quad(>50 \%)\end{array}$ & $31(22.1 \%)$ & $27(19.3 \%)$ & \\
\hline $\begin{array}{l}\text { Completely } \\
\text { endophytic }\end{array}$ & $4(2.9 \%)$ & 0 & \\
\hline Tumor site & & & 0.40 \\
\hline Perihilar & $5(3.6 \%)$ & $3(2.1 \%)$ & \\
\hline Medial margin & $40(28.6 \%)$ & $33(23.6 \%)$ & \\
\hline Lateral margin & $33(23.6 \%)$ & $47(33.5 \%)$ & \\
\hline Anterior aspect & $10(7.1 \%)$ & $11(7.9 \%)$ & \\
\hline Posterior aspect & $52(37.1 \%)$ & $46(32.9 \%)$ & \\
\hline $\begin{array}{l}\text { Preoperative HB level, } \\
\text { mean (SD) }\end{array}$ & $14.2(1.4)$ & $14.4(1.4)$ & 0.21 \\
\hline $\begin{array}{l}\text { Preoperative HTC } \\
\text { level, mean (SD) }\end{array}$ & $42.1(4.4)$ & $42.4(4.0)$ & 0.48 \\
\hline $\begin{array}{l}\text { Preoperative creatinine } \\
\text { level, mean (SD) }\end{array}$ & $0.96(0.45)$ & $0.92(0.29)$ & 0.33 \\
\hline $\begin{array}{l}\text { Preoperative GFR } \\
\text { using MDRD, mean } \\
\text { (SD) }\end{array}$ & $83.3(22.5)$ & $87.3(23.1)$ & 0.15 \\
\hline Surgical technique & & & 0.26 \\
\hline SE $n,(\%)$ & $66(47.1 \%)$ & $75(53.6 \%)$ & \\
\hline Standard PN $n,(\%)$ & $74(52.9 \%)$ & $65(46.4 \%)$ & \\
\hline
\end{tabular}

Table 1 continued

\begin{tabular}{|c|c|c|c|}
\hline & Open NSS & VLP NSS & $p$ \\
\hline Hilar clamping & & & 0.37 \\
\hline Yes $n,(\%)$ & $90(64.3 \%)$ & $97(69.3 \%)$ & \\
\hline No $n,(\%)$ & $50(35.7 \%)$ & $43(30.7 \%)$ & \\
\hline Type of ischemia & & & 0.06 \\
\hline Warm $n,(\%)$ & $135(96.4 \%)$ & $140(100 \%)$ & \\
\hline Cold $n,(\%)$ & $5(3.6 \%)$ & $0(0 \%)$ & \\
\hline $\begin{array}{l}\text { Ischemic time }(\mathrm{min}) \\
\text { mean }(\mathrm{SD})\end{array}$ & $15.7(5.9)$ & $19.9(6.8)$ & $<0.0001$ \\
\hline $\begin{array}{l}\text { Operative time }(\mathrm{min}) \\
\text { mean }(\mathrm{SD})\end{array}$ & $131.2(58.1)$ & $143.0(56.9)$ & 0.09 \\
\hline $\begin{array}{l}\text { Intraoperative blood } \\
\text { loss (cc), mean (SD) }\end{array}$ & $221(399.1)$ & $164(147.8)$ & 0.11 \\
\hline $\begin{array}{l}\text { Delta HB level, mean } \\
\text { (SD) }\end{array}$ & $2.7(3.18)$ & $2.2(1.9)$ & 0.08 \\
\hline
\end{tabular}

HTC Hematocrit

Table 2 Incidence of complications, TRIFECTA, chronic kidney disease (CKD) and eGFR and creatinine level variation, according to the surgical approach adopted

\begin{tabular}{|c|c|c|c|}
\hline & $\begin{array}{l}\text { Open } \\
\text { NSS }\end{array}$ & VLP NSS & $p$ \\
\hline Total & $\begin{array}{l}25 \\
(17.9 \%)\end{array}$ & $21(15 \%)$ & 0.34 \\
\hline Medical & $7(5 \%)$ & $5(3.5 \%)$ & 0.51 \\
\hline Surgical intraoperative & $7(5 \%)$ & $1(0.7 \%)$ & 0.03 \\
\hline Surgical postoperative & $\begin{array}{l}18 \\
(12.9 \%)\end{array}$ & $16(11.4 \%)$ & 0.63 \\
\hline Surgical Clavien II & $9(6.4 \%)$ & $8(5.7 \%)$ & 0.80 \\
\hline Surgical Clavien III & $4(2.9 \%)$ & $7(5 \%)$ & 0.36 \\
\hline TRIFECTA* & $\begin{array}{l}110 \\
(78.6 \%)\end{array}$ & $104(74.3 \%)$ & 0.40 \\
\hline $\begin{array}{l}\text { Preoperative CKD stage III-V } \\
(\%)\end{array}$ & $21(15)$ & $17(12.1)$ & 0.49 \\
\hline $\begin{array}{l}\text { Delta creatinine level pre-op- } \\
\text { 3rd day post-op, mean (SD) }\end{array}$ & $\begin{array}{l}0.05 \\
(0.53)\end{array}$ & $0.21(0.20)$ & 0.02 \\
\hline $\begin{array}{l}\text { Delta creatinine level pre-op-6- } \\
\text { month follow-up, mean (SD) }\end{array}$ & $\begin{array}{l}0.07 \\
(0.20)\end{array}$ & $0.10(0.18)$ & 0.40 \\
\hline $\begin{array}{l}\text { Delta GFR using MDRD pre- } \\
\text { op-3rd day post-op, mean } \\
\text { (SD) }\end{array}$ & $\begin{array}{l}13.1 \\
(14.5)\end{array}$ & $24.4(24.1)$ & 0.008 \\
\hline $\begin{array}{l}\text { Delta GFR using MDRD pre- } \\
\text { op-6-month follow-up, mean } \\
\text { (SD) }\end{array}$ & $1.1(17)$ & $4.1(22.7)$ & 0.19 \\
\hline $\begin{array}{l}\text { New-onset CKD stage III-V at } \\
6 \text {-month follow-up }(\%)\end{array}$ & 0 & $1(0.7)$ & 0.87 \\
\hline
\end{tabular}

functional decrease and no urological complications [9]. In our report at multivariable analysis, the surgical approach was not a predictor of a negative TRIFECTA achievement. The only factors independently associated with a risk of a 
Table 3 Univariable and multivariable analysis for TRIFECTA outcome

\begin{tabular}{|c|c|c|c|c|c|c|}
\hline & \multicolumn{3}{|c|}{ Univariable analysis for TRIFECTA } & \multicolumn{3}{|c|}{$\begin{array}{l}\text { Multivariable analysis for } \\
\text { TRIFECTA not reached }\end{array}$} \\
\hline & Reached & Not Reached & $p$ & $\mathrm{RR}$ & $95 \% \mathrm{CI}$ & $p$ \\
\hline Age, mean (SD) & $62.1(11.7)$ & $64.1(11.3)$ & 0.24 & 1.01 & $0.98-1.04$ & 0.46 \\
\hline Tumor size, mean (SD) & $2.8(0.8)$ & $2.4(0.77)$ & $<0.0001$ & 2.15 & $1.49-3.11$ & $<0.0001$ \\
\hline Surgical approach, $n(\%)$ & & & 0.40 & & & \\
\hline VLP & $104(74.3 \%)$ & $36(25.7 \%)$ & & & & \\
\hline Open & $110(78.6 \%)$ & $30(21.4 \%)$ & & & & \\
\hline \multicolumn{7}{|c|}{ Tumor growth pattern, $n(\%)$} \\
\hline$>50 \%$ exophytic & $171(78.4 \%)$ & $47(21.6 \%)$ & 0.14 & & & \\
\hline$\geq 50 \%$ endophytic & $43(69.4 \%)$ & $19(30.6 \%)$ & & & & \\
\hline \multicolumn{7}{|l|}{ Tumor location, $n(\%)$} \\
\hline Polar & $128(78.5 \%)$ & $35(21.5 \%)$ & 0.33 & & & \\
\hline Mesorenal & $86(73.5 \%)$ & $31(26.5 \%)$ & & & & \\
\hline \multicolumn{7}{|l|}{ Symptoms at diagnosis } \\
\hline Asymptomatic & $178(77.4 \%)$ & $52(22.6 \%)$ & 0.41 & & & \\
\hline Symptomatic & $36(72 \%)$ & $14(28 \%)$ & & & & \\
\hline \multicolumn{7}{|l|}{ Indication } \\
\hline Elective & $184(78.6 \%)$ & $50(21.4 \%)$ & 0.04 & 2.14 & $1.03-4.45$ & 0.04 \\
\hline Relative/absolute & $30(65.2 \%)$ & $16(34.8 \%)$ & & & & \\
\hline
\end{tabular}

negative TRIFECTA achievement were the relative/absolute indication and the clinical tumor size: Each 1-cm increase in tumor size doubled the risk of not achieving TRIFECTA (Table 3). Moreover, no significant difference in operative time, hilar clamping and intraoperative blood loss was observed between the two approaches. While the laparoscopic approach was associated with a significantly mean longer WIT, at multivariable analysis LPN was an independent predictors of a WIT $>25 \mathrm{~min}$. This is in line with most of the recent comparative studies between LPN and OPN, where LPN results constantly associated with a longer WIT, although some authors reported shorter WIT in their LPN series [6, 7, 18, 19]. Consequently, in our LPN cohort a significantly higher eGFR variation on third postoperative day compared to the OPN cohort was observed. However, this significance in eGFR variation was not held after 6-month follow-up, and no significant difference in newonset stage III-V CKD rate at 6-months with baseline follow-up was recorded (Table 2). The similar global renal function results after OPN and LPN are supported by the data from a recent paper by Lane et al. where the authors report after a median follow-up of 6.6 years a median GFR decrease of $16.9 \%$ after LPN and $14.1 \%$ after OPN $(p=0.5)$ [18]. WIT and the quantity of remnant healthy parenchyma are the only modifiable variables able to reduce renal function deterioration after PN [20, 21]. However, although WIT has been strongly associated with acute renal failure, its correlation with chronic renal damage is controversial as other factors such as the width of healthy tissue removed with the tumor and the method of renorrhaphy or the hemostatic energy applied on the surgical bed may play a role in its development [22-27]. In this direction, more detailed biomolecular and imaging tools are needed to assess the real renal damage after this type of surgery [28].

As shown in Table 2, in the present series, no significative differences in total complications were observed after OPN versus LPN, whereas intraoperative SC was significantly higher after the open versus the laparoscopic approach. This is in contrast to a multicenter US experience, where postoperative complication rate was lower in the OPN group (19.2 vs. $24.9 \%$ ), most certainly due to the early worldwide experience with LPN at the time of their study and the inclusion of cT1b RCC, accounting for $8.8 \%$ of all the LPN performed [7].

Furthermore, in our paper, no significative differences between the OPN and LPN groups were observed for surgical Clavien grade II and III complication rates.

At the multivariable analysis, the factors independently associated with SC were clinical tumor size and indication for surgery (relative/absolute vs. elective).

In the present series, the incidence of PSM was not significantly different between patients treated with open and laparoscopic PN. At univariable analysis, the only factor that significantly correlated with the risk of PSM was the type of indication (elective vs. relative/imperative).

To the best of our knowledge, this study is the first matched-pair comparative analysis between OPN and LPN that includes also the simultaneous achievement of the 
TRIFECTA outcomes. Further strengths of our work are the use of clinical dimensions and the stratification of the complications according to the validated Clavien system. Moreover, its multicenter nature might increase the external validity of the data compared with the single-center, single-surgeon setting and provide a valid snapshot of the distribution and outcomes of the open and laparoscopic PN in a European country in the last 4 years.

The main limitation of our report resides in the lack of randomization that might confirm the superiority of one approach over the other, but at present, it seems extremely difficult to perform such a study owing to the difficulties of most skilled laparoscopic surgeons in randomizing patients with clinically T1a renal tumors in the open PN arm, as well as the reluctance of most patients that decided to go for a minimally invasive procedure to be operated by OPN.

Moreover, due to the short-term follow-up available, postoperative renal function was evaluated only at 6 months, using the MDRD formula and not the sequential scintigraphy, that could have allowed a more precise definition of the function of each renal unit.

Another limitation of this study relies on the lack of a validated nephrometric score, since the project began before the Padua and R. E. N. A. L. score systems were developed, although the surgical complexity was evaluated according to multiple variables $[29,30]$.

\section{Conclusions}

No significant differences in achieving the TRIFECTA outcome were reported after OPN and LPN. LPN was associated with a significantly longer WIT compared to OPN. However, the global renal function at 6-month follow-up did not differ significantly between the two surgical approaches.

Conflict of interest None.

\section{References}

1. Kane CJ, Mallin K, Ritchey J et al (2008) Renal cell cancer stage migration: analysis of the National Cancer Data Base. Cancer 113:78-83

2. Ljungberg B, Cowan NC, Hanbury DC et al (2010) EAU guidelines on renal cell carcinoma: the 2010 update. Eur Urol 58:398-406

3. Minervini A, Ficarra V, Rocco F (2011) Simple enucleation is equivalent to traditional partial nephrectomy for renal cell carcinoma: results of a nonrandomized, retrospective, comparative study. J Urol 185:1604-1610

4. Minervini A, Serni S, Tuccio A et al (2012) Simple enucleation versus radical nephrectomy in the treatment of pT1a and pT1b renal cell carcinoma. Ann Surg Oncol 19(2):694-700
5. Porpiglia F, Volpe A, Billia M et al (2008) Laparoscopic versus open partial nephrectomy: analysis of the current literature. Eur Urol 53:732-743 discussion 742-3

6. Marszalek M, Meixl H, Polajnar M et al (2009) Laparoscopic and open partial nephrectomy: a matched-pair comparison of 200 patients. Eur Urol 55:1171-1178

7. Gill IS, Kavoussi LR, Lane BR et al (2007) Comparison of 1,800 laparoscopic and open partial nephrectomies for single renal tumors. J Urol 178:41-46

8. Khalifeh A, Autorino R, Hillyer Sp et al (2013) Comparative outcomes and assessment of Trifecta in 500 robotic and laparoscopic partialnephrectomy cases: a single surgeon experience. J Urol 189(4):1236-1242

9. Hung AJ, Cai J, Simmons MN et al (2013) "Trifecta" in partial nephrectomy. J Urol 189(1):36-42

10. Oken MM, Creech RH, Tormey DC et al (1982) Toxicity and response criteria of the Eastern Cooperative Oncology Group. Am J Clin Oncol 5:649-655

11. Patard JJ, Leray E, Cindolo L et al (2004) Multi-institutional validation of a symptom based classification for renal cell carcinoma. J Urol 172:858-862

12. Greene FL, Page DL, Fleming ID et al (2002) American Joint Committee on Cancer (AJCC) Staging Manual, 6th edn. Springer, Philadelphia

13. Kovacs G, Akhtar M, Beckwith BJ et al (1997) The Heidelberg classification of renal cell tumors. J Pathol 183:131-133

14. Fuhrman S, Lasky LC, Limas L (1982) Prognostic significance of morphologic parameters in renal cell carcinoma. Am J Surg Pathol 6:655-663

15. Dindo D, Demartines N, Clavien PA (2004) Classification of surgical complications: a new proposal with evaluation in a color of 6,336 patients and result of a survey. Ann Surg 240:205-213

16. Rosenbaum PR, Rubin DB (1983) The central role of the propensity score in observational studies for causal effects. Biometrika 70(1):41-55

17. Jasjeet S. Sekhon. Multivariate and propensity score matching software with automated balance optimization: the matching package for R J Stat Soft 42:7 (2011/5)

18. Lane BR, Campbell SC, Gill IS (2013) 10-year oncological outcomes after laparoscopic and open partial nephrectomy. J Urol pii: S0022-5347(13)00004-9

19. Springer C, Hoda MR, Fajkovic H et al (2013) Laparoscopic vs open partial nephrectomy for T1 renal tumours: evaluation of long-term oncological and functional outcomes in 340 patients. BJU Int 111(2):281-288

20. Thompson RH, Lane BR, Lohse CM et al (2012) Renal function after partial nephrectomy: effect of warm ischemia relative to quantity and quality of preserved kidney. Urology 79(2):356-360

21. Thompson RH, Lane BR, Lohse C et al (2010) Every minute counts when the renal hilum is clamped during partial nephrectomy. Eur Urol 58(3):340-345

22. Nguyen MM, Gill IS (2008) Halving ischemia time during laparoscopic partial nephrectomy. J Urol 179:627-632

23. Ng CK, Gill IS, Patil MB et al (2012) Anatomic renal artery branch microdissection to facilitate zero-ischemia partial nephrectomy. Eur Urol 61(1):67-74

24. Simone G, Papalia R, Guaglianone S et al (2012) 'Zero ischaemia', sutureless laparoscopic partial nephrectomy for renal tumours with a low nephrometry score. BJU Int 110(1):124-130

25. Minervini A, Siena G (2012) 'zero ischaemia', sutureless laparoscopic partial nephrectomy for renal tumours with low nephrometry score. BJU Int 110(1):130

26. Minervini A, Siena G, Carini M (2013) Hemostatics for nephronsparing surgery. Expert Rev Med Devices 10(2):153-155 
27. Minervini A, Siena G, Tuccio A et al. (2013) Sutureless Hemostatic Control During Laparoscopic NSS for the Treatment of Small Renal Masses. Surg Innov [Epub ahead of print]

28. Gill IS (2012) Towards the ideal partial nephrectomy. Eur Urol 62(6):1009-1010 discussion 1011-2

29. Ficarra V, Novara G, Secco S et al (2009) Preoperative aspects and dimensions used for an anatomical (PADUA) classification of renal tumours in patients who are candidates for nephronsparing surgery. Eur Urol 56(5):786-793

30. Kutikov A, Uzzo RG (2009) The R.E.N.A.L. nephrometry score: a comprehensive standardized system for quantitating renal tumor size, location and depth. J Urol 182(3):844-853 